\title{
Being and Becoming a Leader: Arabian Gulf Women Managers' Perspectives
}

\author{
Ikhlas A. Abdalla ${ }^{1}$ \\ ${ }^{1}$ College of Business Administration, Kuwait University, Kuwait \\ Correspondence: Ikhlas Abdalla, Department of Management and Marketing, College of Business \\ Administration, Kuwait University. P.O.Box 5486 Safat, 13055 Kuwait. E-mail: \\ iabdalla@hotmail.com/iabdalla@cba.edu.kw
}

Received: October 14, 2014

Accepted: November 22, 2014

Online Published: December 20, 2014

doi:10.5539/ijbm.v10n1p25

URL: http://dx.doi.org/10.5539/ijbm.v10n1p25

\begin{abstract}
This study examines the challenges and opportunities of Kuwaiti, Emirati and Qatari female managers at the major milestones of their career paths, and also explores their perceptions of Arab women leadership competencies. Questionnaires responses of 84 Kuwaiti, 47 Emirati and 43 Qatari female lower/middle managers were used, and 63 of them were interviewed. The findings of the three samples were similar, and they indicated that the main barriers were formal and informal gender-discrimination practices, trivialization of female skills and scholarship, difficulty in accessing certain professions and cross-gender social network and support. Lack of 'formal' mentoring systems and female role-models were considered of a lesser value compared to the difficulty in accessing significant social network at work. Balancing work and life responsibilities was not as a major problem as in the West. Male relatives were often perceived as either major hindrances or great help. The respondents perceived themselves as high-potential employees who were as assertive and competitive as their male counterparts, and relatively more cooperative and androgynous leaders. They also saw themselves as more cooperative, competitive, assertive and career-oriented than the average Arabian Gulf working woman. The respondents did not see the average working woman in a stereotypical way, except for the notion that 'women lack workplace political savviness'. Mostly, the findings were consistent with regional and international literature, however patriarchy, gender-biased legal and organizational systems and dictated traditional gender-roles augmented the career challenges of Arabian Gulf women. The findings were discussed within the region's socio-political context.
\end{abstract}

Keywords: Arab, women manager, gender, career experiences, leadership potential, conservative culture

\section{Introduction}

The Arab region has the world's lowest ratios of women representation not only in managerial positions but also in employment in general, and in politics (World Economic Forum [WEF], 2013), despite the fact that in several Arab countries women's average education is higher than men's (Arab Fund for Economic \& Social Development [AFESD], 2013; WEF, 2013). Also, the region scores the world's highest ratios of female economic inactivity, gender-gap in economic activity and unemployment - where women unemployment ratios are double those of men (AFESD, 2013; United Nations Development Program [UNDP], 2013). Within the Arab region, the Gulf Cooperation Council (GCC) countries have the largest mismatch between the levels of female education and workforce participation. For example, in Kuwait, Qatar and Emirates the ratios of women in the total workforce were $23 \%, 20 \%$ and $12 \%$ respectively while their ratios in tertiary education were $70 \%, 67 \%$ and $85 \%$ respectively (Table 1). In politics, women of the GCC countries seem to be even more hidden, as only Kuwaiti women have full political rights which they received in 2005 (Table 1). In contrast, women in some Arab countries got their political rights in 1950s. The high education of Arabian Gulf women and their low female employment, political representation and public participation go against not only human rights requirements but also against the logic of economic efficiency, particularly in light of the heavy dependency of the Gulf economies on expatriate male labor force. Expatriate labor in Kuwait, Qatar and Emirates represents $66 \%, 78 \%$ and $82 \%$ of the total labor force, making them the countries with the highest stock of migrant labor in the world (Forstenlechner \& Rutledge, 2014).

However, in spite of the underutilization of Arabian Gulf female potential, the roots of the problem were seldom 
studied. Omair (2008), in her review of research on Arab working women, concluded that the majority of the scant research on this topic was from 2000 onwards, and was concentrated on few broad topics explaining societal norms that were responsible for women's positions in public and private spheres. Recent studies (e.g., Jamali et al., 2005; Karam \& Afioni, 2013; McElwee \& Al-Riyami, 2003, Tlaiss, 2010) suggested that Arab women career barriers were similar to those of Western women, in addition to the impact of the patriarchy. They also indicated that due to the severity of the barriers, women's accumulating managerial education and experiences did not seem to assist except few to reach middle managerial levels (Jamali et al., 2005). This is apparent from Table (1) which shows that in Kuwait, Emirates and Qatar women represent $14 \%, 11 \%$ and $7 \%$ of the 'legislators, senior officials and mangers' category.

Previous studies on Arab women (Jamali et al., 2005; Karam \& Afioni, 2013; Metcalfe, 2006, 2007, 2008; Tlaiss, 2010) presented multiple barriers that operate at different levels (personal, organizational and macro barriers) and also interactively (Karam \& Afioni, 2013). Among the most salient career barriers were gender stereotyping, overt and subtle gender discrimination, obsolete human resource policies, clubbism (difficulty in accessing cross-gender networks), patriarchy, strongly gendered legal systems and poor governance. The few studies on women's career facilitators (Karam \& Afioni, 2013; Kauser \& Tlaiss, 2011) suggested that family background, family support, education, inner drive for success and self-confidence had positive effects on women's career (e.g., Karam \& Afioni, 2013; Omair, 2008, 2010; Wilkinson, 1996). Family support plays a significant role in Arab women career advancement. Omair (2008) explained that this support may be a result of a traditional practice where women are expected to consult with and take the permission of their men (husbands or fathers) before making career decisions. Once permission is granted Arab men support their women in any way they can, either directly by giving opportunities or by giving advice and encouragement, (Omair, 2008). These factors, obviously, determine the equity of distribution of opportunities and power and hence influence women career strategies and success.

However, despite the recent increase in studies on Arab working women, most of the studies were in the form of surveys tracking the numbers of women managers in different countries (Omair, 2008). Hence, there is urgent need to continue to seek, at individual country and regional levels, more appropriate explanations for the low representation of women in the public sphere so that the gender imbalance in managerial positions can be addressed (Kauser \& Tlaiss, 2011). Within this context this study used samples of Kuwaiti, Emirati and Qatari female managers to address the following main questions:

i. What societal patterns impacted the respondents' decisions and experiences at the major milestones of their careers?

ii. How did gender-role socializations, gender-role stereotyping and self-concepts affect their careers?

iii. What were the effects of "distribution of opportunities" (gender access to learning and training, information, mentors, advocates), "distribution of power" and empowerment/disempowerment on their career progress?

iv. How did their individual professional competencies influence their progress?

v. How do they perceive the potential talent of Arab working women?

The three countries (Kuwait, Emirates and Qatar) were chosen because they offer similar economic, social, political, ecological and legal contexts as well as similar female empowerment opportunities. All Arabian Gulf countries are very small monarchies (Kuwaiti, Emirati and Qatari populations were 3.8, 7.9 and 1.9 respectively; Table 1). They are oil/gas rich countries with some of the highest per capita incomes in the world (average male estimated income was $\$ 40,000$; and the estimated earned income ratio female/male ranged from 0.42 to 0.83 (Table 1). Also, Table (1) presents several relevant economic and social indicators which reveal the similarities between the countries under study. 
Table 1. Key demographic and economic indicators of Kuwait, Emirates and Qatar and gender gap indices, 2013

\begin{tabular}{|c|c|c|c|}
\hline Indicators & Kuwait & Emirates & Qatar \\
\hline Population & 2.8 & 7.9 & 1.9 \\
\hline Population growth & 3.8 & 4.9 & 6.1 \\
\hline Population sex ratio $(\mathrm{M} / \mathrm{F})$ & 1.48 & 2.3 & 3.1 \\
\hline Percentage of women in the workforce & $23.9 \%$ & $14.8 \%$ & $12.4 \%$ \\
\hline Gender equity wages for similar jobs (survey) ratio $\mathrm{F} / \mathrm{M}$ & .66 & .74 & .77 \\
\hline Estimated earned income (PPP US\$) Female & $\$ 23,385$ & $\$ 16,637$ & $\$ 33,234$ \\
\hline Estimated earned income (PPP US\$) Male & $\$ 40,000$ & $\$ 40,000$ & $\$ 40,000$ \\
\hline Estimated earned income (PPP US\$) ratio F/M & 0.58 & 0.42 & 0.83 \\
\hline Legislators, senior officials and managers & $14 \%$ & $11 \%$ & $7 \%$ \\
\hline Professional and technical workers & $34 \%$ & $28 \%$ & $20 \%$ \\
\hline Percentage of enrolment in tertiary education (female) & 25.6 & 35.7 & 31.0 \\
\hline Percentage of enrolment in tertiary education (males) & 11.0 & 17.4 & 5.0 \\
\hline Enrolment in tertiary education ratio $\mathrm{F} / \mathrm{M}$ & 2.33 & 2.05 & 5.60 \\
\hline Women in parliaments (year 2014) & 0.00 & 0.00 & 0.00 \\
\hline Women in ministerial positions (year 2014) & 0.04 & 0.22 & 0.00 \\
\hline \multicolumn{4}{|l|}{ Gender Gap Index 2013 (out of 136 countries) } \\
\hline Rank in Overall Gender Gap Index & 116 & 115 & 115 \\
\hline Rank in 'Economic participation gender-gap index' & 115 & 106 & 106 \\
\hline Rank in 'Political empowerment gender-gap index' & 126 & 135 & 135 \\
\hline Rank in 'Education attainment gender-gap index' & 57 & 53 & 53 \\
\hline
\end{tabular}

Sources: World Economic Forum, Global Gender Gap Report, 2013 and AFESD Unified Arab Report, 2013.

Thus, this paper focuses on exploring the career journey of Arabian Gulf women and also how they perceive themselves as managers. The rationale for this focus is that this group includes some of the most educated and perhaps highly career aspirant women who are in the pipeline, or get into the pipeline, to many top corporate positions. These women, while they have not yet completed the journey to the executive suite, they do have valuable experiences in their journeys so far. Thus, it is important to examine their career experiences and self-concept. Given the fact that the voices of this group are largely omitted there is a pressing need to hear them. Thus, the study is expected to offer information which may be of value to scholars, practitioners and young aspirant women. A set of questionnaires and interviews provided quantitative and qualitative data from 174 women managers. The paper begins with summarizing the literature on career facilitators and barriers of women mangers and highlights the contextual dynamics within which working Arab women operate. The research methodology is then presented and the findings outlined and discussed, relevant recommendations are presented.

\section{Literature Review}

\subsection{Review of Literature on the Arab World}

As it is clear from the discussion above and the indicators in Table (1), Arab women improved human capital has not eliminated gender disadvantages in the public sphere, (Al-Lamki 2006; UNDP, 2013; WEF, 2013; World Bank [WB], 2010), and women managers cluster at the lower level even in sectors like education where they are the majority (El-Ghannam, 2002). The systematic gender inequalities which are common across the Arab region were attributed to Islamic teaching and deeply entrenched Urf (societal norms) particularly patriarchal kinship patterns, social subordination and ingrained male dominance (e.g., Abdalla 1996; Kauser \& Tlaiss, 2011; Rizzo, Abdel-Latif \& Meyer, 2007; UNDP, 2005; Wilkinson, 1996). While researchers agree on the adverse role of Urf on women's economic and political participation, there is partial disagreement on the exact role of Islamic religion in impeding women careers. For example, Metcalfe (2011), Metcalfe \& Mutlag (2011) and Rizzo et al. (2007) argued that $u r f$ did not originate from Islam, it originated from tribal norms and traditional customs some 
of which were pre-Islamic. Abdalla (1996) and Elamin and Omair (2010) stated that Islam was not against women economic participation, in fact it encourages it. In this regard, Abdul Ghani (2011) and Kauser and Tlaiss (2011) argued that conservative male dominated politico-religious centers of power, because they strongly believed that a woman's place was at her home, used Urf as a potential source for interpreting Qura'an and establishing Islamic laws (Sharia).

On the other hand, some researchers, i.e., Sidani $(2005)$ and Metcalfe $(2006,2008)$ argued that the Arab gender ideology was partly grounded on the acknowledgement by the Qura' an of the 'biological differences between men and women and that they had complementary roles in life'. The notion of the biological differences prescribed Arab gender relationships and roles (Metcalfe, 2006, 2007) which assumes that a woman will marry early; her contribution to the family will be as homemaker; the man leads, financially supports and protects his household (Metcalfe, 2011). The 'male custodianship', stated in the Qura'an, was used by traditional male family members to exercise their authority over women in all areas of decision-making that relates to the private and public spheres (Moghadam, 2005), often disregarding women education and work experience, and the requirements of modern life (Metcalfe, 2011).

Besides the adverse influence of the traditional social forces Arab women have to deal with sexist legal systems (Moghadam, 2005), particularly the Personal Status Law which are considered an embodiment of gender discrimination in the region (Alami, 2013; Metcalf \& Mutlag, 2011). They are considered prime forces behind the 'mismatch' between the influx of qualified women to the labor market and poor employment opportunities and provisions prescribed by gender-biased legal systems and governance structures (Jamali et al., 2005; WB, 2014). These arguments were further substantiated by a recent study of the World Bank (WB, 2014). It found that, among 134 countries, the Arab countries (particularly GCC countries) scored the greatest gender-disparity in their business laws concerning six areas: accessing institutions, using property, getting a job, providing incentives to work, building credit and going to court.

The Arab failure to achieve gender parity was also attributed to poor governance, the practice of linking women's economic rights policies to political regimes' interests, rather than to the principles of women's empowerment, equality and inclusive development visions (Alami, 2013; Shah \& Al-Qudsi, 2009). Further, due to poor governance, attempts to infuse better gender parity in existing laws often gave rise to a reaction back to conservative views and positions, resulting in reviews of existing laws or the promulgation of new ones that are less liberal than the 'official' declarations, or emerging social norms and practices (e.g., the Kuwaiti Parliament's rejection of the 2004 government proposal to give women their full political rights; AFESD, 2006).

One more predicament is created by development planners who customarily evaluate women's needs on the basis of the traditional gender roles (Alami, 2013). Thus, new policies often keep women at secondary ranks even when the purpose is to incorporate them in the economy. In this respect, AFESD (2006) cited GCC countries' attempts to restructure the workforce-over $60 \%$ of which is expatriate workers - using native women to meet the needs of the service sector (employed mainly in education and social service) without consideration for their preferences, ambitions, capacities or skills.

\subsection{Brief Review of Non-Arab Research}

The well documented Tokenism Theory (Kanter, 1977), the glass-ceiling concept and other related studies provided helpful frameworks that enhanced the understanding of the challenges and environmental dynamics impacting women economic status (see the literature review of Broadbridge \& Hearn, 2008; Broadbridge \& Simpson, 2011; Eagly \& Carli, 2007). For example, these studies suggest that in situations involving token representation of women, men being the dominant group at work seemingly feel uncomfortable working with women and hence they may heighten cultural boundaries by exaggerating their camaraderie, emphasizing their differences from the women, reinforcing gender stereotyping and excluding women from informal interactions where critical information is exchanged. Tokenism may also encourage organizational practices of segregating jobs by gender and biased personnel practices in favor of men. Due to these practices and to women heightened visibility (as "different" group members) women are more likely to be under performance pressures and they may feel a need to perform better than their male colleagues to prove themselves. They also tend to feel that they are not a good-fit in the male-dominated culture or that they need to change in some way to fit in. Moreover, they are more likely to end up with few same-gender role models, mentors and networks, and face restricted access to mentors/networks of any gender and to critical developmental opportunities and geographical mobility (Broadbridge \& Hearn, 2008; Lyness \& Thompson, 2000). Also, the literature suggests that women leaders may face a conflict between what they think are more effective leadership behaviors and what others consider appropriate for them based on gender-role stereotypes. For example, Nelson and Levesque (2007) indicated that 
women who wished to be influential or effective cannot be too self-assured or too assertive without violating gender stereotypes; although in the hiring stage they were chosen for the position because they were assertive. On the other hand, if they speak tentatively rather than assertively they are judged as being less competent (Budworth \& Mann, 2010).

Further, the literature (e.g., Broadbridge \& Hearn, 2008; Broadbridge \& Simposon, 2011) suggests that the majority of women, regardless of their organizational level, attribute success primarily to factors within their purview (e.g., merit and effort), followed by the socio-psychological factors, (Keeton, 1996). In this respect, Broadbridge, (2008), Broadbridge and Hearn, (2008), and Budworth and Mann, (2010) explained that a good track record (professional portfolio and hard work) may enable women to partially overcome the negative consequences of gender related socio-psychological and systematic factors (e.g., negative gender stereotypes in male gender-typed positions). Other strategies which may help women in overcoming organizational barriers are taking a proactive approach to managing their own careers, utilization of their social support, having developmental assignments, mentors and role models, developing interpersonal relations, self-promotion and circumventing social isolation especially at the higher organizational echelons where networking with men in powerful positions is one of the most significant requirements for advancement (Lyness \& Thompson, 2000).

\subsection{Chronological Background Information}

At this juncture, it may be useful to present further contextual background in the form of chronological review of the factors that determined women's gains and setback since the mid of the $20^{\text {th }}$ Century.

1950s-60s: Arab women movement started at the beginning of the $20^{\text {th }}$ Century (UNDP, 2005). In 1950s -60 s, women in many Arab countries obtained their right to vote and stand for parliamentary elections. However, the Arab governments were not and still are not completely genuine in their support of women's cause as will become apparent later (UNDP, 2005).

1970s-1980s: In 1970s, women in many Arab countries (most notably Tunisia, Egypt, Iraq and Sudan), achieved significant progress under military regimes. They were given some of their civil and economic rights, and a few were appointed in ministerial and other leadership position. Those actions were taken by political dictatorships in order to appease international agencies which were putting them under pressure for their human rights violations. However, in reality they confined women-movements within their political frameworks by attaching the movement to the political-power structure and/or allowing it to work under the surveillance of the government radars (ESCWA, 2006). An additional predicaments that started escalating since the $70 \mathrm{~s}$ was the growth of Islamic extremism. Some of the Arab political dictatorships saw in the Islamic political groups a means to weaken leftist and labor union movements. The governments' assistance of the Islamic fundamentalists enhanced their influence and their ability to attack the women movements and gains. In response, moderates and anti-Islamic fundamentalism called for the restriction of 'Islam' to the realm of personal and spiritual values; and they criticized Islamists for basing their ideology on custom and not the Islamic religion, (Jawad, 1998; Sidani, 2005).

While women were treading a path strewn with obstacles Tunisian women, since the seventies, have gained several rights (personal, political and economic) through the decrees of a dictator. Contrary to the predictions of the Islamists, 'equal status of Tunisian women to men in many paradigms' was smoothly implemented within the Tunisian Islamic society. In the 1980s, women movements saw qualitative upswing, especially in the 'Arab Maghreb' countries (French-speaking North African countries) which started to copy the Tunisian model. However, all women movements in the region, including the Tunisian's, continue to work under the States' radars (ESCWA, 2006).

1990s: In the 1990s, the international agenda witnessed fundamental changes, with increased emphasis on human rights and democratic change. United Nations agencies pushed for the empowerment of women by linking of external aid to improvements in the condition of women. Internal pressure started mounting. Hence, many rulers encouraged 'token' representation of women in parliaments, cabinets and public institutions (Fayad, 2004). Thus the issue of women's rights and rise continue to be a type of political façade (ESCWA, 2006).

2000s onward: In the 2000s, the international community had more intense interest in Arab women plights in the aftermath of 11 September 2001, and the revelation of Afghani women predicament. International attention shifted to cultural factors, a core agenda focused on expanding women opportunities (ESCWA, 2006). The Gulf States finally succumbed to internal and international pressures, however, only Kuwaiti women were given their political rights in 2005. Certainly pro-women legislative amendments would not have passed the hurdle of fundamentalists' opposition had it not been for the direct governments' support to women and the efforts of civil societies (Al-Kazi, 2011). 
While the political regimes are reluctantly assisting women cause, the hostile position of legislators towards gender equality was seen as a major barriers of women rise. Ironically many Arab legislators seem to take a stand that contradicts their Constitutions which call for gender equality in all aspects of life. Their stand also opposes the provisions of international conventions agreements (CEDWA [Convention on the Elimination of All Forms of Discrimination Against Women] and other related agreements), (Sidani, 2005). Often, jurists who are opponents of women rights ground their position in Salafi (most conservative) Islamic fundamentalist jurisprudence and custom asserting men's superiority to and guardianship of women (Kelly \& Breslin, 2010). Consequently the 'Personal Status Law' defines women as minors in need of their male relatives in matters relating to their rights of marriage, divorce, child care, employment, travel, and even the entitlement of children to their mother's citizenship, (Sidani, 2005; UNDP, 2005). As a result of the 'anti-women rights' positions of the legislators the Arab legislative systems was ranked as the most gendered in the world (WB 2014). Consistent with these argument are the findings of a study of Dubai Women Establishment ([DWE]; 2009) which indicated that $42 \%$ of the 100 surveyed Arab women leaders pointed to three main challenges facing Arab women in their ascent to the top: religious understanding and/or misinterpretation, and legal and cultural environments. In contrast, they considered education and the political system as their enablers. However, government's duplicity regarding women rights issues seems to be a pretense that persists till the present. For example, all Arab countries ratified/endorsed CEDAW but they put forward specific reservations on articles ensuring gender equality such as 'the realization of the principle of gender equality; the right of women to conclude contracts, administer property and be equal in all stages of court and tribunal procedures; the right of women in marriage, divorce and child custody; and the right of women to acquire, change, retain a nationality and pass it on to their children'.

\section{Method}

\subsection{Sample}

The study used convenience sampling and snowball (Bryman, 2004) approaches to collect quantitative and qualitative data from Kuwaiti, Emirati and Qatari female lower and middle managers. It is important to note that given the small sizes of the native population- i.e., below 0.5 million in Qatar and below 1.5 in Kuwait and UAE - getting access to bigger samples of native female managers was challenging. Natives represent about $10 \%, 15 \%$ and $33 \%$ of the Qatari, Emirati and Kuwaiti populations, respectively. In total, completed questionnaires were received from 84 Kuwaiti, 47 Emirati and 43 Qatari (i.e. 174 questionnaires). Sixty three of the respondents who completed the questionnaires were also interviewed. Eighty six percent of the respondents worked in the public sector and $83 \%$ of them had Bachelor's degrees and $17 \%$ with postgraduate degrees, $22 \%$ of the respondents got some training or education in advanced countries. The respondents' ages ranged from 27 years to 53 years; $71 \%$ were married and most have children.

\subsection{Research Instruments}

The questionnaires were based on Broadbridge (2008), Gupton and Slick (1996) and Lyness and Thompson (2000) and largely adapted based on the findings of previous regional research in order to suite the Arab situation. The general outlines of the questionnaires and interviews were borrowed from Gupton and Slick (1996). The questionnaires allowed for both concise, quantitative responses as well as short answer/essay responses that were qualitative in nature. Consequently, the data were rich with information. It covered the following dimensions:

i. Career path: The questionnaires asked about major barriers and opportunities encountered along career paths at these critical points: a) Choosing a major area of study or career; b) Obtaining the necessary degree or training; c) Securing a job after college; d) Advancing the career.

ii. Leadership traits and behavior: The respondents were asked to compare themselves with their male counterparts and with average Arabian Gulf working women in general regarding the following 9 leadership attributes and using a three-point scale (they possess 'more', 'same' or 'less' of the attribute than their male counterparts or the average working woman).

iii. Significant life influences affecting career: The respondents were asked in the interviews and the questionnaires about the persons who had significant influences in their careers such as mentors, positive role-models, negative role-models and other social/professional support resources. With respect to mentors and role-models, the respondents were asked to describe the mentoring they received and their most significant role models (negative and positive). The study sought information about the role model and/or mentor including the role model's or mentor's relationship to respondent, their gender, age, and main traits. The terms "role model" and "mentor" were defined. Positive role model is "one whom the respondent admired and tried to emulate, but may not have known personally". A negative role model is "one whose characteristics or behavior the respondent 
have tried to avoid". A mentor is "one with whom the respondent formed a professional, interpersonal relationship and who provided beneficial career and psychological support to her".

iv. Women career barriers: The respondents were asked to state their agreements or disagreements, using a scale of 5 points, regarding 28 statements about: a) stereotypical views about Arabian Gulf women's competencies and behaviors, and b) the impact of environmental factors on Arab women careers.

v. Best advice: The respondents were asked to give their 'best advice' for women aspiring to be leaders.

The second phase of data collection consisted of series of interviews which were carried out subsequent to the initial questionnaires. The aim of the interviews was to get the interviewees' stories about their ascent to the managerial positions. The storytellers were encouraged to speak freely about their personal experiences and to disclose any information that they felt important to share. A set of narrative prompts was given to the interviewees few days before the interview and it included the following points: i) chronicle of her path to the top; ii) experiences with preparations programs in her profession; iii) personal and professional landmarks; iv) negative and positive experiences and moments; v) significant life influences affecting career. sources of strength, support and motivation; vi) barriers encountered; vii) how women's status has changed since she entered the profession; viii) any accommodations and compromises she made because of her gender; ix) advice for women aspiring to leadership positions; $\mathrm{x}$ ) any regrets; and xi) future career plans. The qualitative part of the questionnaire and the interviews asked respondents to share any additional thoughts. The interviews were about 40 minutes in length and they were carried out by researchers who were native of the country concerned; tape-recorded and later written verbatim hard copies were produced and analyzed.

\section{Analyses and Findings}

Between-country comparisons using One-Way Analysis of Variance (Post Hoc Tests) showed that there were few significant differences between the three countries as is shown below. Hence, for the issues where there were insignificant differences between the three countries the overall averages (aggregates) were used. This is considered acceptable because the three countries were very similar in many important details (Table 1). The quantitative and qualitative findings were extracted from the responses to the questionnaires and interviews. The narrative parts of the questionnaires and interviews were used to complement the quantitative data and make it more meaningful. This section will first present the experiences, opportunities and challenges encountered by the respondents along their career path at the following critical points: choosing a major area of study or career, securing a job after college, and advancing career. Then the respondents' assessments of their leadership potential and the reasons why they accepted the managerial positions will be presented.

\subsection{Choosing a Major Area of Study/Career}

Recalling an earlier phase of their lives namely, their education phase, the respondents reported that dictated social roles seemed to influence their choice of fields of study and types of jobs and economic sectors. Females' traditional fields were education, social sciences and medical sciences - the latter were not available to older members of our sample. Many respondents indicated that choosing the fields of study and careers were not their decisions alone. Male members of the family and in some cases their mothers had the final say. They also reported that because of lack of information about labor market needs, job vacancies/postings, recruitment agencies and career counseling, their decisions were based on their personal preferences, teachers' suggestions and random guesses. The only employment office available is a government central agency that places jobseekers in different government departments. Those who attempted to work in the private sector, pursue nontraditionally occupations or education that required travel abroad were often discouraged.

Another set of problems pertain to college admission policies. Many Arab universities impose admission ceilings to limit the numbers of female students in different colleges and hence give preference to male candidates. That is, the admission requirements are higher for female than male students. These policies still exist despite the fact that they violate the Constitution which calls for gender equality in every respect. Also, until a decade ago Qatar and Emirates did not allow women to enroll in engineering schools despite the fact that the absolute majority of the highest academic achievers across the Arab world were women (AFESD, 2006; UNDP, 2005). It is worth noting, however, that all levels of education in the three countries are gender-segregated, but none of the respondents complained from gender discrimination in students' grading or quality of education. The only point raised was the unfair admission policies and students stipends, as they are paid less than men. Of course, there is the personal mistakes which went unprotected because of lack of career information and counseling. Fifty three percent of the respondents expressed their regret for their choice of academic study. One respondent stated that, "I studied physical education just because my brother did so. It limited my career but not his; he is happily working in the private sector." 


\subsection{Getting the First Job}

The respondents recalled a number of problems they encountered in their pursuit of their first job after graduation. Many respondents commented that it was not common for graduates to get fair employment opportunities. Often candidates were not chosen on the basis of their abilities. They argued that good employment opportunities often required big family names or "Wasta" (i.e., use of powerful social connections and nepotism). Also, social norms forced them to work in certain sectors e.g., the public/government sector. Some of those who sought other sectors in Qatar and Emirates were confronted with the fact that they would be the 'only woman' in the company; an unacceptable situation in a conservative culture. However, it must be mentioned that the public sector is where Arab women, particularly Arabian Gulf women, gravitate (Karam \& Afioni, 2013), and it is attractive to native males too because it offers natives better employment packages (e.g., less working hours, higher salaries, high job security and longer vacation days) than the private sector.

\subsection{Advancing Career}

It was found that most of the barriers at this phase were clustered around the following themes:

Theme 1 - Discrimination against women: The individual accounts frequently contained not one but many accounts of discriminatory treatment because of gender. The respondents strongly believe that the traditional Arab culture, dominant male chauvinism, and gender-biased business legislations and human resource policies were the main roots of their career barriers. About $80 \%$ of the respondents approved of statements indicating that 'the dominant societal believe was that women were more suitable for domestic chores than public work". They also approved the statements stipulating that, "Often women get token appointment and consequently find themselves left out of the power structure and important decisions" (69\%); "Women need to work harder than men to be recognized by seniors" (72\%); "Women earn less than men for the same job' $(90 \%)$ ); "women often lack freedom of geographical mobility which impedes their impedes their career advancement" (63\%; Table 2).

The interviews suggested that women, irrespective of their specialization and competence, were and still are likely to be offered employment in the administrative divisions of the organization (such as public relations and human resources) and service sectors (such as education and social service); and the interviews were littered with evidence of glass-ceiling, glass-wall and sticky-floor policies applied on female employees. Also, the respondents' accounts suggested several incidences of nepotism and clubbism. For example, members of certain tribes/families and well-connected individuals often have faster career tracks than the rest. Thus, the most important challenge might be the perceived gender-biased human resource practices. In this regard an Emirati respondent said, "The number-one area of biased treatment was 'being given less respect' and 'being left out of the dominant male network of managers' ...the clubbism, patronizing attitudes keep me from being taken very seriously. I must say, I am treated politely by males but not respected as equal".

Theme 2 - Balancing family and career: Sixty eight of the respondents felt that they managed - usually with the help of others - to balance family and career responsibilities and to be comfortable and guilt-free about their accomplishments. Thus, child rearing and household chores were not considered very important hindrances, as was the case in Western countries, because most respondents had house help and much shorter working day compared to their Western counterparts. A potential source of work/family conflict could be a male family members, for example, having an unsympathetic father or husband was reported by some as a major hindrance to their education and career development. Permissions of male family members are essential for females' decisions pertaining to choosing a line of education, further education, employment and even business travel. Then again, most of the respondents believed that the support of their husbands, fathers or brothers had been vital for their success.

Theme 3 - Social networks at work: Overall, women had difficulty developing the alliances they needed because 'older male managers, typically favor protégés who are younger versions of themselves'. One respondent explained that, "Because women who enter male fields are often seen as outsiders and because people are brought up in a gender-segregated settings at home, school and everywhere, women rarely have equal access to counselling as their male colleagues. And because of the concern about ones' reputation, they are often not part of the casual network of relationships formed at work and they find themselves on the edge rather than in the middle of the professional, socialization process." However, other respondents admitted that they did not make the time to network when it is accessible. Lack of work socialization might lead to lack of backing of key players which may exasperate the unfair distribution of opportunities especially with respect to promotion and significant training (Kauser \& Tlaiss, 2011).

Theme 4 - Mentors and role-models: The findings showed that $85 \%$ of the respondents had positive role models and $74 \%$ had negative role models. Seventy three of the respondents had informal mentors. It is important to 
note that formal mentoring is not used in Arab organization and there is no equivalent Arabic word for 'a mentor'. The findings revealed that $94 \%$ of the respondents reported that the most widespread behaviors exhibited by the respondents' mentors were: 'Subtle training without expecting credit (quietly supportive)', and "Communicating, responding, good listening and informing". The second frequently exhibited mentoring behaviors were, "Advising and counseling" and "Motivating, encouraging growth and risk taking", while "Sponsoring (opening doors, providing opportunities)" and "Role-modeling" are less used. Also, 85\% of the respondents reported that they had been mentors to someone.

With respect to role-models, the findings showed that $91 \%$ of the respondents had people in their lives that they admired and tried to emulate and $77 \%$ of them had negative role-models whose characteristic/behavior they tried to avoid. The most common role-models were the respondents' supervisors, teachers, colleagues, fathers, mothers and/or brothers. The most frequently mentioned behavior/traits of positive role-models were perseverant, wise, ethical, humble and caring (compassionate). For the negative role-models, the common traits/behaviors were overbearing, negative, corrupt, egotistical, phony, ignorant and indecisive. Curiously, most of the negative role-models were women, which needs further future investigation. However, one explanation might be that the respondents seemed to learn from the mistakes of women - being from the same gender - than men. It is worth noting that the importance of mentors and role-models were often overlooked by the interviewees. However, when they were reminded of it, they did acknowledge the positive impact of their mentors and role-models on their career success.

Theme 5 - Women associations and caucuses: Only $9 \%$ of the respondents were women activists and/or were members of women caucuses. About half of the respondents were not members but intend to be part of such networks in the future, while 37\% did not see the need to join such networks. An Emirati respondent commented, "... they lack the voice and the stamina". Some of the respondents indicated that they shun these associations because of their political orientations, their focus on appeasing the regime's more than women's causes, or they lacked the competencies; or because the respondents' busy schedules did not allow for such participation. In this respect UNDP (2005) indicated that the Arab governments restricted the freedom of action of all civil societies including women's. They often monopolized and monitored the movement's discourse, leaving only limited scope for women's initiatives and demands.

Theme 6 - Political Savviness: Most respondents stated that, earlier in their career they did not understand organizational politics and bureaucracies. A Kuwaiti respondent stated, "The problems for women are not the formal, tangible barriers, such as education or certification, but the intangible, informal ones that require an aspirant to be accepted as "one of us" by her seniors." A Qatari respondent stated, "You need the necessary education, experience and skills but they do not guarantee you a good position, you also need advocates". Many respondents said that political naivety and lack of backing of key players within the organization were serious hindrances to their careers. They later realized that among the critical drivers of career success was political awareness of the system and how it functioned. Some attributed lack of political awareness to the social customs which discouraged cross-gender socialization, hence seniors hardly knew them.

Theme 7 - Self-concept: Some respondents looked inward and focused on their own personal problems with gender-role stereotypes or on how they have dealt with this problem. One respondent stated, "I felt discomfort entering a traditionally male domain ... have faced many obstacles within my own self-perception. I grew up in a much protected environment in the $70 \mathrm{~s}$. ... learned not to take comments to heart and ignored gender-biased comments. I remained focused, worked longer, harder".

Theme 8 - Women leaders' professional competencies: The respondents strongly believed that Arab women leaders, in general, were as competent as men ( $83 \%$ of the respondents), more sensitive and compassionate to peoples' needs than men (79\%), capable of influencing people and successfully accomplishing the task (81\%), good organizers, multitasker, and focus on accomplishing the task (88\%), skilled in financial management $(92 \%$ of the respondents), effective mediators $(83 \%)$, career ambitious $(75 \%)$, tend to be participative leaders $(80 \%)$, and androgynous leaders (81) (Table 2). 
Table 2. Respondents' assessment of stereotypical beliefs about Arab working women and other career barriers

\begin{tabular}{|c|c|c|c|c|c|c|}
\hline Stereotypical Beliefs about women's & $\begin{array}{l}\text { Total } \\
\%\end{array}$ & $\mathbf{X}$ & SD & $\begin{array}{l}\mathbf{K} \\
\mathbf{X}\end{array}$ & $\begin{array}{l}\mathbf{E} \\
\mathbf{X}\end{array}$ & $\begin{array}{l}\mathbf{Q} \\
\mathbf{X}\end{array}$ \\
\hline 1. Many women in my country are seeking jobs only and not careers & 52 & 3.2 & 1.2 & 3.3 & 3.2 & 3.1 \\
\hline 2. Most female non-managerial employees support women managers & 44 & 3.1 & 1.0 & 3.3 & 3.2 & 2.8 \\
\hline 3. Women leaders are as competent as men & 83 & 4.1 & 1.1 & 4.2 & 4.3 & 3.8 \\
\hline 4. Women are more sensitive and capable to deal with people's matters than men & 79 & 4.1 & 1.0 & 4.0 & 4.1 & 4.1 \\
\hline 5. Compared to men, most women have insignificant influence in decision making & 53 & 3.2 & 1.1 & 3.1 & 3.4 & 3.5 \\
\hline 6. Women are incapable of financial finesse & 8 & 1.9 & 1.0 & 1.9 & 2.0 & 1.9 \\
\hline 7. Women lack delegation skills and tend to centralize authority & 20 & 2.3 & 1.1 & 2.2 & 2.4 & 2.4 \\
\hline 8. Career women are frequently torn between family and work responsibilities. & 68 & 3.7 & 1.2 & 3.4 & 3.6 & 4.0 \\
\hline $\begin{array}{l}\text { 9. Women often lack freedom of geographic mobility which impedes their career } \\
\text { advancement }\end{array}$ & 72 & 4.0 & 1.2 & 3.9 & 4.0 & 4.2 \\
\hline 10. Women are frequently perceived in stereotyped roles & 86 & 3.9 & 1.1 & 3.9 & 3.9 & 3.8 \\
\hline 11. Women are not politically savvy & 37 & 3.0 & 1.1 & 2.9 & 3.0 & 3.1 \\
\hline 12. Women earn less than men for the same job & 90 & 4.4 & 0.8 & 4.5 & 4.5 & 4.3 \\
\hline $\begin{array}{l}\text { 13. Many women get token appointments, consequently they are left out of the power } \\
\text { structure \& important decisions }\end{array}$ & 69 & 3.7 & 1.0 & 3.9 & 4.0 & 3.8 \\
\hline $\begin{array}{l}\text { 14. Women are more capable than men at managing teams and collaborative work } \\
\text { efforts }\end{array}$ & 65 & 3.7 & 1.1 & 3.6 & 3.8 & 3.6 \\
\hline 15. In general, women managers are more client-oriented than men managers & 63 & 3.8 & 1.0 & 3.8 & 3.8 & 3.8 \\
\hline 16. Often, women are not good mediators & 17 & 2.3 & 1.1 & 2.4 & 2.5 & 2.1 \\
\hline 17. Usually, capable of influencing people \& accomplishing the task & 81 & 4.1 & 1.0 & 4.0 & 4.3 & 4.0 \\
\hline $\begin{array}{l}\text { 18. In general, women are good organizers, multi-taskers \& can keep focused on what } \\
\text { needs to be accomplished }\end{array}$ & 88 & 4.4 & 0.8 & 4.5 & 4.5 & 4.1 \\
\hline 19. Generally, women value personal relationships more than power & 69 & 3.7 & 1.0 & 3.7 & 3.6 & 3.7 \\
\hline 20. Innate gender differences account for the ways men and women think & 62 & 3.4 & 1.3 & 3.3 & 3.9 & 3.0 \\
\hline $\begin{array}{l}\text { 21. No amount of training or education will make women and men work or manage } \\
\text { alike }\end{array}$ & 53 & 3.1 & 1.4 & 2.8 & 3.2 & 3.2 \\
\hline 22. Generally, women have no aspiration to assume leadership positions & 25 & 2.3 & 1.2 & 2.1 & 2.4 & 2.4 \\
\hline 23. Women need to work harder than men to be recognized by seniors & 72 & 4.0 & 1.1 & 3.9 & 4.1 & 4.2 \\
\hline 24. The Arab culture firmly defines the roles of male and female leaders. & 90 & 4.2 & 1.1 & 4.1 & 4.1 & 4.2 \\
\hline 25. In general women do not have enough role models & 41 & 2.9 & 1.2 & 2.9 & 2.7 & 2.9 \\
\hline 26. A key inhibitor of women careers is the legal system & 85 & 4.3 & 0.8 & 4.3 & 4.5 & 4.2 \\
\hline $\begin{array}{l}\text { 27. The dominant societal believe was that women were more suitable for domestic } \\
\text { chores than public work }\end{array}$ & 80 & 4.2 & 1.0 & 4.1 & 4.3 & 4.1 \\
\hline 28. Women education is their main career weapon & 94 & 4.4 & 1.1 & 4.5 & 4.6 & 4.5 \\
\hline
\end{tabular}

Note. K stands for Kuwait, E stands for Emirates and Q stands for Qatar.

Scale used: $5=$ Strongly agree, $4=$ Agree, $3=$ =Undecided, $2=$ Disagree, $1=$ Strongly disagree.

Percentage values presented in $2^{\text {nd }}$ column of this Table are totals of \% scores of 4 (Agree) and 5 (Strongly agree).

When the respondents were asked to compare their leadership characteristics with their male colleagues in nine leadership traits, they reported that they were, generally, as assertive and competitive as their male counterparts, but more "cooperative" (72\% of the respondents) and "family orientation" (69\%) and 'androgynous' ([people and task oriented] 79\%) than their male colleagues. Further, they considered themselves less motivated by "power" and "money" than men. An interesting comment put forward by a Kuwaiti manager in support of androgynous leadership was, "I have worked with two generations of women, the first were 'personal-relations oriented' and often sought acceptance of others while the latter generation imitated men's job behavior. I hope that the next generation would be in the middle and have the best of the masculine and the feminine traits" (Table 3). Also, the respondents were asked to compare themselves with "the average Arabian Gulf working woman" using the nine personal attributes indicated above, the respondents reported that they perceived themselves as more "cooperative" (73\% of the respondents), "confidently assertive" (60\%), "competitiveness" (63\%), and "career oriented" (61\%) than the average Arab working woman.

When the respondents were asked about why they were chosen for their present position and why did they accept it, half of the respondents believe that they were promoted to the leadership positions because "they were the 
best qualified for the position in terms of experience". Other important reasons were: "they had excellent managerial skills" (39\%) and/or "the promotion was a reward for very hard work" (45\%). They also reported that a key reason for their acceptance of the leadership position was to make "a positive impact on organization performance" (88\%). Other reasons, which were of much lower importance, were: "work in a challenging job", "self-fulfillment and gratification", "better salary" and/or "because of encouragement from others". They generally expressed their satisfaction with their present positions (78\%), 92\% felt connected to their immediate work group and believed that their subordinates were comfortable with them as their superiors.

Table 3. The respondents' perceived leadership traits compared with their male counterparts

\begin{tabular}{lcccccccc}
\hline Perceived leadership trait compared with male peers' & Total & & $\mathrm{K}$ & $\mathrm{E}$ & $\mathrm{Q}$ & $\begin{array}{c}\text { One-way } \\
\text { variance }\end{array}$ \\
\cline { 2 - 8 } & & & & & & $\mathrm{X}$ Analyses of \\
\hline Confidently Assertive and daring & 51 & 2.4 & .71 & 2.7 & 2.1 & 2.4 & $\mathrm{~K}: \mathrm{E}(\mathrm{P}<.002\}$ \\
Competitive & 56 & 2.5 & .61 & 2.7 & 2.5 & 2.4 & $\mathrm{~K}: \mathrm{E}(\mathrm{P}<.02\}$ \\
& & & & & & & $\mathrm{K}: \mathrm{Q}(\mathrm{P}<.01\}$ \\
Cooperative & 74 & 2.7 & .5 & 2.8 & 2.7 & 2.6 & \\
Motivated by money & 16 & 1.6 & .6 & 1.7 & 1.5 & 1.5 & \\
Motivated by power & 13 & 1.6 & .7 & 1.6 & 1.6 & 1.5 & \\
Concerned about personal relationships & 55 & 2.4 & .8 & 2.3 & 2.3 & 2.6 & \\
Task oriented & 65 & 2.6 & .6 & 2.9 & 2.6 & 2.4 & $\mathrm{~K}: \mathrm{Q}(\mathrm{P}<.01\}$ \\
Family oriented & 72 & 2.7 & .6 & 2.6 & 2.7 & 2.7 & \\
Androgynous & 70 & 2.6 & .7 & 2.8 & 2.4 & 2.6 & \\
\hline
\end{tabular}

Note. K stands for Kuwait, E stands for Emirates and Q stands for Qatar.

Three-point scale used: $3=$ more than male counterparts, $2=$ same, 1=less.

Percentage values shown in $2^{\text {nd }}$ column represent those whose answer was “more than male counterparts'.

Table 4. The respondents' perceived leadership traits compared with those of average working women

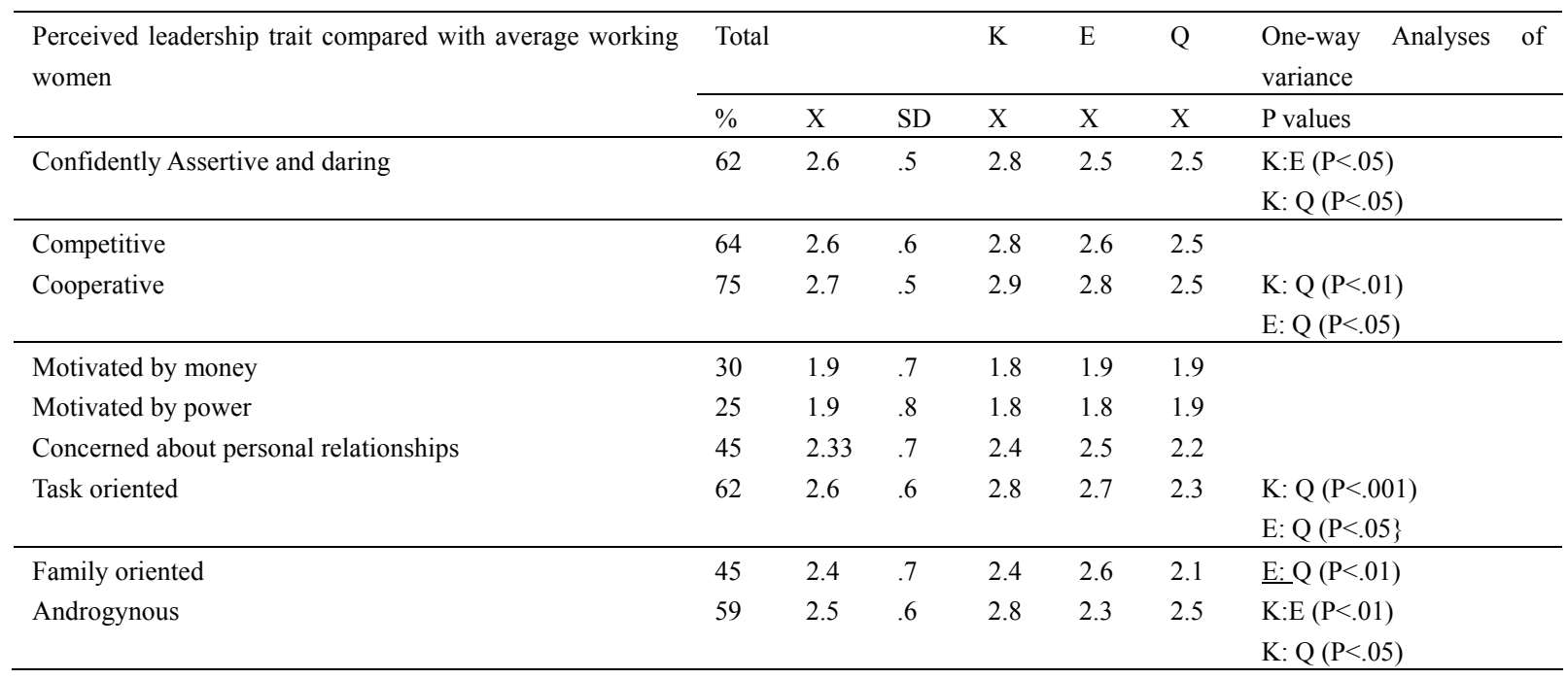

Note. K stands for Kuwait, E stands for Emirates and Q stands for Qatar.

Three-point scale used: $3=$ more than average women, $2=$ same, $1=$ less.

Percentage values shown in $2^{\text {nd }}$ column represent those whose answer was "more than average women'.

Theme 9 - The respondents' "best advice": When the respondents were asked for their "best career advice" to help/empower younger female generations, they frequently stated that "women need to not only have a strong work ethics but also the willingness to work harder than their male counterparts'. Thus, it seems that today's female managers, similar to those a decade ago, sense that they are still having to prove their worth (as a gender) in roles that continue to be sanctioned by the culture of the organization and by society as more appropriately filled by males. Representative remarks are: "Excel in your work, make sure that you know more and produce more. Do the best possible and respect will come" and "Women can lead just as well as men, but they must work 
much harder to get to the same level. Prove your worth! Men don't always need to do this; just being a male is sufficient!" Although working hard and excelling on the job were clearly perceived as "musts" to advance, none of the respondents suggested that diligence alone was usually sufficient to succeed. The "Hard work" advice was always coupled with other career strategies and tactics, many of which pertain to development of a number of critical traits such as professionalism (be principled, courageous and don't whine). Some respondents pointed to the need to control the gender-bias first; a Kuwaiti manager stated, "I have a simple message to policy makers, 'Stick to the Constitution!'”.

\section{Discussion and Conclusions}

What have we learned from and about Arabian Gulf women managers? Several interesting findings need to be underscored:

First: The women in the three countries had similar experiences, concerns and visions, and their experiences were consistent with the findings of previous Arab and international literature, however their career barriers were more intense than those reported on Western women (Huse \& Solberg, 2006; Jamali et al, 2005; Karam \& Afioni, 2013; Metcalfe \& Mutlag, 2011). Hence, it seems that the women's issues raised by the respondents were generally 'universal', and only the magnitude of the barriers is country specific. For example, the greatest differences between the Arab results and Western results were the severe impact of the patriarchy and the gender-biased legal/formal practices (WB, 2014). Thus, the battle grounds of the Arab women are wider and harsher.

A peculiar characteristic of the Arab traditional culture is that it encourages girls' education but often discourages women from displaying their intelligence. Once their education was completed, there was no or little external social encouragement, support or guidance to turn them into high achievers in the professional fields. The respondents indicated that the discriminatory managerial practices in favor of men were rampant even in organizations/industries where women were a majority (e.g., the education sector). Hence, women were prevented from obtaining the more central and strategic career opportunities and experiences, and they find themselves at a disadvantage when competing with men for managerial positions. As suggested by Abdalla (2006), in male-dominated cultures bright women find themselves hidden from each other and living in "A Land of Lost Dreams".

Second: It is apparent that the respondents did not see the average Arabian Gulf working women in a stereotypical way; they also believed that they were more cooperative and androgynous leaders than their male counterparts. It is interesting to note the speedy progress of the respondents' faith in women's talent and competence that was unmatched by an equivalent change in the general societal value systems. These results support previous research findings that showed that women had more egalitarian attitudes towards women than men (Abdalla, 1996; Broadbridge, 2011; Lyness \& Thompson 200; Metcalfe 2011). Broadbridge and Hearns (2008) and Metcalfe and Mutlag (2011) argued that women leaders tended to score better than men on leadership characteristics and styles because a fierce weeding-out process takes place among women managers and hence those who survive were usually the very best. Also, the literature (see Broadbridge \& Simpson, 2011; Metcalfe \& Mutlag, 2011) suggested that the 'facilitating skills' - inherent in transformational leaders - and the androgynous personality attributes might come more naturally to women because of early socialization patterns, yet both genders use it effectively.

Third: The findings showed that, at the public level, cross-gender alliances and networking were often socially unacceptable and when women were willing to participate, access was extremely difficult. Thus, women, by being deprived of networking might end up being deprived of the advocacy of powerful organization members, which is often considered a major vehicle used in job placements, training and promotions decisions (Broadbridge \& Simpson, 2011; Karam \& Afioni, 2013; Kauser \& Tlaiss, 2011). Apparently, in this environment women cannot fight their cases or have fair opportunities without the support of their men and other advocates. Hence, many respondents gave tribute to the roles played by their fathers and husbands in their education and career success. It is interesting to note that while the respondents encountered difficulties in finding the support they needed (networks, powerful advocates, mentors, role-models) most of them were reluctant to be active participants in women caucuses; and some were skeptic about its abilities to change the gender-biased policies. Thus, the respondents by not using the caucuses to reach out and help other women might have failed to 'practice what they preach'.

In sum, the respondents believed that many working women neither lack aspiration for leadership positions nor do they lack the necessary educational qualifications, merit and leadership talent. They were particularly concerned about lack of women's developmental opportunities and trivialization of their leadership skills, 
scholarships and talents, and the lack of good support systems and opportunities to prove their worth. Obviously, barriers and obstacles exist for anyone when pursuing lofty career goals. No one expects the road to be gilded, however neither should one expect to find the path loaded with land mines!! The responses were filled with unnecessary problems created more often than not by the mere fact that they were of a particular gender. Relatively few complaints were made that did not in some way relate back to the fact that the person happened to be a female in a society that has made her gender take precedence over her competency and potential in her chosen career. Arab organizations desperately need to tap the leadership potential among its throng of women professionals to ensure that work organizations have the best leadership available. Stereotyped notions about who should and should not be doing the job is essential to provide the kind of leaders organizations need to equip them for the complexities of the $21^{\text {st }}$ century. It is important to indicate at this juncture that the voices heard here and which support the international literature are those of elite Arab women, the well-educated women. The concerns, attitudes and visions of the less experienced/skilled working women may be different and need to be investigated.

\section{Concluding Remarks}

Karam and Afioni (2013) argued that due to the limited literature on Arab women and human resource (HR) practices, research papers pertaining to this topic need to devote much of their analysis to broad-level factors impacting the levels of gender equity in HR systems. Thus, with the aim of facilitating the development of fairer employment, this paper addressed the career barriers of Arab women managers by linking several macro-level factors (most notably, the gendered national legislative systems and the intersection between Isalm, Urf and patriarchy), with organizational-level factors (e.g., governance system and HR policies and practices), and micro-level factors (e.g., women mangers' perceived traits). The findings of the present research validated the findings of Karam and Afioni (2013), Keeton (1996), Budworth and Man (2010), Metcalf (2011), the WB (2014) and UNDP (2013). Consistent with previous research findings is the analogy revealed by the present findings between the Arab women managers' challenges inside their organizations (i.e., at the mezzo level) and those facing them outside the organization (i.e., at the macro level). Also, the present findings substantiated previous findings in that the factors within the female professionals' purview (i.e., the micro level factors, such as education and hard work) were perceived to be the main facilitators of their careers while the mezzo and macro social systems were the main inhibitors.

The findings of this study revealed a number of general recommendations to enhance the roles of HR professionals, nation's legislatures and other professional in alleviating the current gender bias, albeit providing specific recommendations pertaining to these issues lies beyond the scope of this paper. However, following the general guidelines provided by Morely et al (2006) and Karam and Afioni (2013) and given the fact that a core determinant of gender equality are HR policies, one could presume that localizing gender equity in HR systems requires tackling the gender discrimination issues from many fronts and at multiple levels: at the macro, organizational and individual employee levels.

\section{References}

Abdalla, I. A. (1996). Attitudes towards women in the Arabian Gulf Region. Women in Management Review, 11(1), 29-39. http://dx.doi.org/10.1108/09649429610109271

Abdalla, I. A. (2006). Human resource management in Qatar. In P. S. Budhwar, \& K. Mellahi, (Eds.), Managing Human Resources in the Middle East (pp. 121-144). Abingdon: Routledge.

Abdul Ghani, H. (2011). Urf-o-Adah (Custom and Usage) as a source of Islamic law. American International Journal of Contemporary Research, 1(2), 178-185.

AFESD. (2006). Unified Arab Economic Report. Abu Dhabi publishers, Abu Dhabi (in Arabic).

AFESD. (2013). Unified Arab Economic Report. Abu Dhabi publishers, Abu Dhabi (in Arabic).

Alami, N. (2013). Waiting for the bloom: Correcting policy biases against Arab women's economic rights, paper prepared for the expert group meeting. Women and Economic Empowerment in the Arab Transitions, 21-22.

Al-Kazi, L. (2011). Women and non-governmental organizations in Kuwait: A platform for human resource development and social change. Human Resource Development International, 14(2), 167-181. http://dx.doi.org/10.1080/13678868.2011.558313

Al-Lamki, S. (2006). The development of human resources in the Sultanate of Oman: Omanization and the Role of Women. Unpublished presentation at the Sultan Qaboos Cultural Center, Summer Institute on Oman and Gulf, Washington, D.C. 
Broadbridge, A. (2008). Senior careers in retailing: An exploration of male and female executives' career facilitators and barriers. Gender in Management: An International Journal, 23(1), 11-35. http://dx.doi.org/10.1108/17542410810849105

Broadbridge, A., \& Hearn, J. (2008). Gender and management: new directions in research and continuing patterns in practice. British Journal of Management, 19, 38-49. http://dx.doi.org/10.1111/j.1467-8551.2008.00570.x

Broadbridge, A., \& Simpson, R. (2011). 25 Years on: reflecting on the past and looking to the future in gender management research. British Journal of Management, 22, 470-483.

Bryman, A. (2004). Social Research Methods. Oxford: Oxford University Press,

Budworth, W., \& Mann, S. (2010). Becoming a leader: the challenge of modesty for women. Journal of Management Development, 29(2), 177-186. http://dx.doi.org/10.1108/02621711011019314

DWE (2009). Arab Women Leadership Outlook 2009-2011. DWE, Dubai.

Eagly, A. H., \& Carli, L. L. (2007). Through the labyrinth: The Truth about How Women Become Leaders. Boston, Massachusetts: Harvard Business School Press.

Elamin, A. M., \& Omair, K. (2010). Male attitudes towards working females in Saudi Arabia. Personnel Review, 39(6), 746-766. http://dx.doi.org/10.1108/00483481011075594

El-Ghannam, A. R. (200). Analytical study of women participation in economic activities in Arab soceities. Equal Opportunities International, 21(1), 1-8. http://dx.doi.org/10.1108/02610150210787037

ESCWA. (2006). Report on Arab Women Conditions: Women's Movement in the Arab World. UN, New York.

Fayad, M. (2004). Women's participation in political life: conducive and obstructive factors. In Issues of Citizenships in Lebanon: Dimensions and Challenges.

Forstenlechner, I., \& Rutledge, E. J., (2014). The GCC's "demographic imbalance": perceptions, realities and policy options. Middle East Policy Council, 13(4).

Gupton, S. L., \& Slick, G. A. (1996). Highly Successful Women Administrators: The Inside Stories of How They Got There. California: Corwin Press.

Hausmann, R., Tyson, L. D., \& Zahidi, S. (2013). The Global Gender Gap Report 2013. Geneva: World Economic Forum.

Jamali, D., Sidani, Y., \& Safieddine, A. (2005). Constraints facing working women in Lebanon: an insider view. Women in Management Review, 20(8), 581-594. http://dx.doi.org/10.1108/09649420510635213

Jawad, H. A. (1998). The Rights of Women in Islam: An Authentic Approach. New York, NY: St. Martin's Press,.

Kanter, R. M. (1977). Men and Women of the Corporation. New York: Basic Books.

Karam, C. M., \& Afiouni, F. (2013). Localizing women's experiences in academia: multilevel factors at play in the Arab Middle East and North Africa. International Journal of Human Resource Management, 25(4), 500-538. http://dx.doi.org/10.1080/09585192.2013.792857

Kauser, S., \& Tlaiss, H. (2011). The Arab woman manager: participation, barriers, and future prospects. Journal of International Business and Economy, 12(1), 35-56.

Keeton, K. B. (1996). Characteristics of successful women managers and professionals in local government: a national survey. Women in Management Review, 11(3), 27-34. http://dx.doi.org/10.1108/09649429610117434

Kelly, S., \& Breslin, J. (2010). Women's Rights in the Middle East and North Africa: Progress Amid Resistance. London: Rowman \& Littlefield Publishers.

Lyness, K. S., \& Thompson, D. E. (2000). Climbing the corporate ladder: do female and male executives follow the same route? Journal of Applied Psychology, 85(1), 86-101. http://dx.doi.org/10.1037/0021-9010.85.1.86

McElwee, G., \& Al-Riyami, R. (2003). Women entrepreneurs in Oman: some barriers to success. Career Development International, 8(7), 3339-3346. http://dx.doi.org/10.1108/13620430310505296

Metcalf, B. D. (2006). Exploring cultural dimensions of gender and management in the Middle East. Thunderbird International Business Review, 48(1), 93-107. http://dx.doi.org/10.1002/tie.20087

Metcalf, B. D. (2007). Gender and human resource management in the Middle East. International Journal of 
Human Resource Management, 18(1), 54-74. http://dx.doi.org/10.1080/09585190601068292

Metcalfe, B. D. (2008). Women, management and globalization in the Middle East. Journal of Business Ethics, 83(1), 85-100. http://dx.doi.org/10.1007/s10551-007-9654-3

Metcalfe, B. D. (2011). Women, empowerment and development in Arab Gulf States: a critical appraisal of governance, culture and national human resource development frameworks. Human Resource Development International, 21(2), 131-148. http://dx.doi.org/10.1080/13678868.2011.558310

Metcalfe, B. D., \& Mutlag, L. (2011). Women, leadership and development: reappraising the value of the feminine in leadership theorizing in the Middle East. In B. D. Metcalfe, \& F. Mimouni (Eds.), Leadership Development in the Middle East (pp. 328-370). Cheltenham: Edward Elgar.

Moghadam, V. (2005). Women's economic participation in the Middle East. Journal of Middle East Women's Studies, 1(1), 110-146. http://dx.doi.org/10.2979/MEW.2005.1.1.110

Morley, L., Gunawardena, C., Kwesiga, J., Lihamba, A., Odejide, A., \& Shackleton, L (2006). Gender equity in selected commonwealth universities: an examination of sustainable interventions in selected commonwealth universities. London: Department for International Development

Nelson, T., \& Levesque, L. (2007). The status of women in corporate governance in high growth, high-potential firms. Entrepreneurship Theory and Practice, 31(2), 209-232. http://dx.doi.org/10.1111/j.1540-6520.2007.00170.x

Omair, K. (2008). Women in Management in the Arab Context. Education, Business and Society: Contemporary Middle Eastern Issues, 1(2), 107-123. http://dx.doi.org/10.1108/17537980810890293

Omair, K. (2010). Typology of career development for Arab women mangers in the United Arab Emirates. Career Development International, 15(2), 121-143. http://dx.doi.org/10.1108/13620431011040932

Rizzo, H., Abdel-latif, A., \& Meyer, K. (2007). The Relationship between gender equality and democracy: a comparison of Arab vs. non-Arab muslim societies. Sociology, 41, 1151-170. http://dx.doi.org/10.1177/0038038507082320

Shah, N., \& Al-Qudsi, S. (2009). Female work roles in traditional oil economy: Kuwait. Research in Human Capital and Development, 6, 213-246.

Sidani, Y. (2005). Women, work, and Islam in the Arab societies. Women in Management Review, 20(7), 498-512. http://dx.doi.org/10.1108/09649420510624738

UNDP. (2013). Human Development Report: Rise of the South-Human Progress in a Diverse World. New York: UNDP.

UNDP. (2005). Arab Human Development Report: Towards the Rise of Women in the Arab World. UNDP Regional Bureau for Arab States. Jordan: National Press.

Wilkinson, G. (1996). Women in Business. Dubai: Gulf Business.

World Bank. (2010). Middle East and North Africa Region: Bridging the Gap, Improving the Capabilities and Expanding Opportunities for Women in the Middle East and North Africa. Washington: World Bank.

World Bank. (2014). Women, Business and the Law 2014: Removing Restrictions to Enhance Gender Equality. Washington: World Bank.

\section{Copyrights}

Copyright for this article is retained by the author(s), with first publication rights granted to the journal.

This is an open-access article distributed under the terms and conditions of the Creative Commons Attribution license (http://creativecommons.org/licenses/by/3.0/). 